\title{
Leak detection method for electrohydraulic injectors of diesel engines in operation
}

\author{
Yakimov Igor V. \\ Automobile Transport Department \\ Irkutsk National Research Technical University \\ Irkutsk, Russia \\ E-mail: igor_auto@mail.ru \\ Bondarenko Elena V. \\ Automobile Maintenance and Repair Department, \\ Orenburg State University \\ Orenburg, Russia
}

\author{
Krivtsov Sergey N. \\ Automobile Transport Department \\ Irkutsk National Research Technical University \\ Irkutsk, Russia \\ E-mail: Krivcov_sergei@mail.ru \\ Krivtsova Tatyana I. \\ Automobile Transport Department \\ Irkutsk National Research Technical University \\ Irkutsk, Russia \\ E-mail: tatyana_krivcova1985@mail.ru
}

\begin{abstract}
Modern automobiles equipped with an accumulator fuel-delivery system can fulfill the most demanding operational and ecological requirements. However, when fueldelivery components (predominantly, electrohydraulic injectors) break down, it is difficult to analyze their faults.
\end{abstract}

Therefore, studies aimed to decrease diagnosis time, enhance informativity and accuracy and develop methods for continuous injector's health control, and fault prediction are topical.

The issue is lacking data on the parameters of common rail injector, return line leaks. It makes it difficult to identify extreme conditions of accumulator fuel-delivery system's injectors.

The research aims to determine the relations between injector's conditions and leakage parameters and to develop methods for identifying individual leaks in order to localize the injector's faults.

The research methods are a set of analytical and experimental researches using existing analytical approaches, tools and equipment and special methods and devices.

The research results are dependencies of Common Rail injectors' conditions on the parameters of individual leaks, methods for determining the parameters of individual common line leaks, equipment applied for implementation of these methods.

\section{Keywords-Common Rail; fuel injector; leakage}

\section{INTRODUCTION}

Modern automobiles equipped with an accumulator fueldelivery system can fulfill the most demanding operational and ecological requirements [1]. However, when fuel-delivery components (predominantly, electrohydraulic injectors) break down, it is difficult to analyze their faults [2].

The study focuses on application of diesel engine's accumulator fuel-delivery system diagnostics methods for injector's health diagnostics. It analyzes fuel leaks in electrohydraulic injectors [2]. It is necessary to determine relations between these leaks, cyclic delivery and internal parameters of injectors.

It was identified that the most meaningful parameter characterizing electrohydraulic injectors is fuel leakage for cyclic delivery control [3, 4] which depends on the wear of surfaces of injector's parts. It makes it possible to predict their life cycles. It is evident that fuel injection control leaks depend on the wear of injector's parts, their dynamic instability due to the wearing [5], and violation of regulating parameters.

Having studied the components of return line leaks, one can obtain diagnostics data on conditions of the electrohydraulic injectors.

The electrohydraulic injector of the diesel engine equipped with an accumulator fuel system is a crucial component, which is responsible for the fuel delivery quality [6]. It can influence performance parameters, diesel and automobile reliability. Most faults of accumulator fuel systems are faults of electrohydraulic injectors.

\section{THEORETICAL BACKGROUND}

Injectors operate in a wide range of delivery variations. The criteria of their proper operation are presented in the following expression: 


$$
\left.\begin{array}{l}
q_{i}^{\min } \leq q_{i} \leq q_{i}^{\max } \\
Q_{i} \leq Q_{i}^{\lim }
\end{array}\right\}
$$

where $q_{i}$ is the cyclic delivery of the $i$-th operation mode, $\mathrm{mm}^{3} ; q_{i}^{\min }, q_{i}^{\max }$ are the values of minimum and maximum admissible cyclic deliveries of the $i$-th operation mode, $\mathrm{mm}^{3}$; $Q_{i}$ and $Q_{i}^{\text {lim }}$ are nominal and admissible values of fuel injection control leaks, $\mathrm{mm}^{3} / \mathrm{sec}$.

Structural and regulating parameters influence the performance of injectors [7]. Each parameter influences the cyclic fuel delivery. However, the value of leaks in the return rail is more closely related with structural parameters. Therefore, detailed analysis of their causes is a crucial task [2]. Let us analyze fuel leaks in a typical common rail injector [2] (Figure 1).

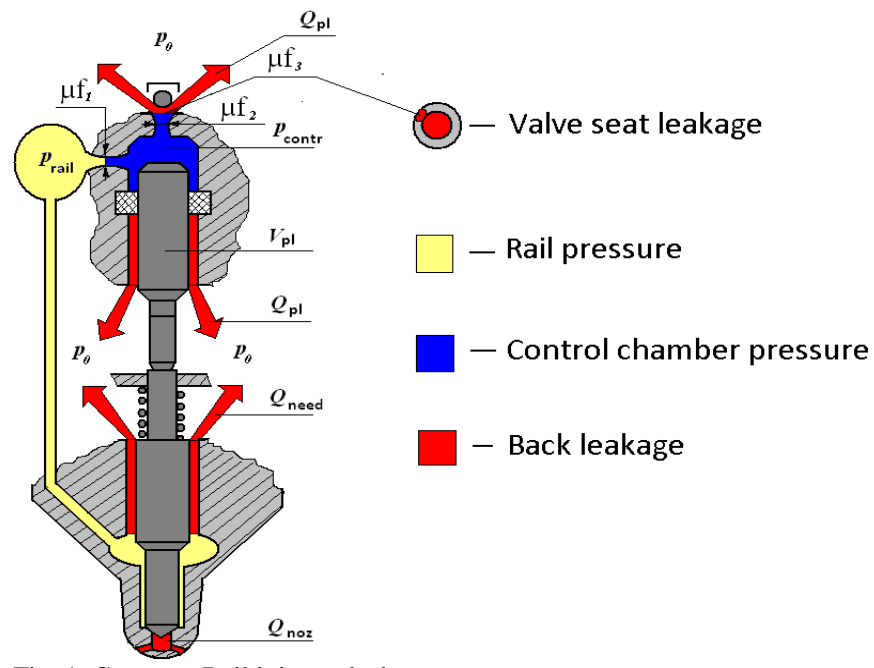

Fig. 1. Common Rail injector leaks.

Fuel leaks to a drain low-pressure hole. There are two types of leaks - static (when there is no control signal) and dynamic (when there is a control signal). Fuel leaks to the return line through clearances of the valve needle and its guides, a plunger-multiplier and its seal, and a control valve.

The total return line leakage can be written as:

$$
Q_{\text {back }}=Q_{s t}+Q_{d y n}
$$

where $Q_{s t}$ is fuel leakage through clearances and seals.

The static leaks (through clearances and seals) are a sum of leaks through the guide of a pilot plunger, valve and leaks thorough a cylindric guide of the nozzle needle [2]. The nozzle density in the flare section is ignored as injectors lose their operation capacities, which can cause serious faults of parts. Thus:

$$
Q_{s t}=Q_{p l}+Q_{v a l}+Q_{n e e d}
$$

where $Q_{p l}$ - leaks through plunger seals; $Q_{v a l}$ - leaks through clearances of the control valve; $Q_{\text {need }}-$ leaks through the clearance of the nozzle needle.
The dynamic leaks depend on the amount of fuel leaking through the control valve and changes in its volume due to movements of the pilot plunger [8,9]:

$$
Q_{d y n}=Q_{v a l}+\frac{d V_{p l}}{d t}=Q_{v a l}+\frac{d z_{p l}}{d t} \cdot \frac{\pi d_{p l}^{2}}{4}
$$

where $V_{n л}$ is the changes of the fuel volume due to pilot plunger movements;

$\frac{d z_{p l}}{d t}$ is the plunger movement velocity rate; $d_{p l}$ is the pilot plunger diameter; $Q_{v a l}$ is fuel leaks through the control valve.

It is evident that dynamic leaks $\left(Q_{d y n}\right)$ depend on regulating, and static leaks - on structural $\left(Q_{s t}\right)$ injector's parameters. It determines the basis of a diagnostics method by return line leaks.

Diagnostics based on the return line leakage involves measurement of fuel leakage through the delivering line and fuel return line in different modes, including the mode when injectors are disconnected from the control signal in order to stabilize the fuel flow in the return line and ensure measurement accuracy. The values of target leaks are calculated. The method increases the volume of diagnostics data.

First, the value of the individual dynamic injection control leakage to the return fuel line is determined. Then, the values of individual cyclic delivery fuel and static injector control fuel are determined.

The components of the total return line leakage are as follows:

$$
Q_{b a c k}=Q_{s t 1}+Q_{d y n 1}+Q_{s t 2}+Q_{d y n 2}+Q_{s t 3}+Q_{d y n 3}+Q_{s t 4}+Q_{d y n 4}
$$

Total dynamic fuel leakage:

$$
Q_{d y n}=Q_{d y n 1}+Q_{d y n 2}+Q_{d y n 3}+Q_{d y n 4} .
$$

Total static fuel leakage:

$$
Q_{s t}=Q_{b a c k}-Q_{d y n}
$$

Assuming that the control signal of the first cylinder has been switched off, the return line leakage is:

$$
Q_{s t 1}=Q_{b a c k}-\left(Q_{d y n}+Q_{s t 2}+Q_{s t 3}+Q_{s t 4}\right)
$$

The value of return line leaks $\left(Q_{s t i}\right)$ in injectors with faulty control valves and sealing intersections of needle valves and pilot plungers is larger than the value of leaks in injectors with admissible parameters of these components.

The relation of the cyclic delivery and dynamic leakage is a dependence characterizing the efficiency of the dynamic cyclic delivery leakage which depends on static leaks. 
Accordingly, the following expressions can be written as follows.

Individual dynamic leakage:

$$
\begin{gathered}
Q_{d y n}=Q_{b a c k}-\sum_{i=1}^{n-1} Q_{d y n i}-Q_{s t} \\
Q_{s t 1}=\left(\frac{q_{1}}{Q_{d y n 1}}\right) \cdot \frac{\left(Q_{b a c k}-Q_{d y n}\right)}{\sum_{i=1}^{n-1}\left(\frac{q_{i}}{Q_{d y n i}}\right)}
\end{gathered}
$$

\section{METHODS AND MATERIAL}

A mathematical model of EHI processes $(5,6,8,9)$ was created in GT-SUITE (Fig. 2). The mathematical model of an injector can be used for its analytical analysis and comparison with bed test results in order to determine dependencies of injector's conditions on injection control leakage. The model is based on technical parameters of $0445110376 \mathrm{BOSCH}$ injectors (5).

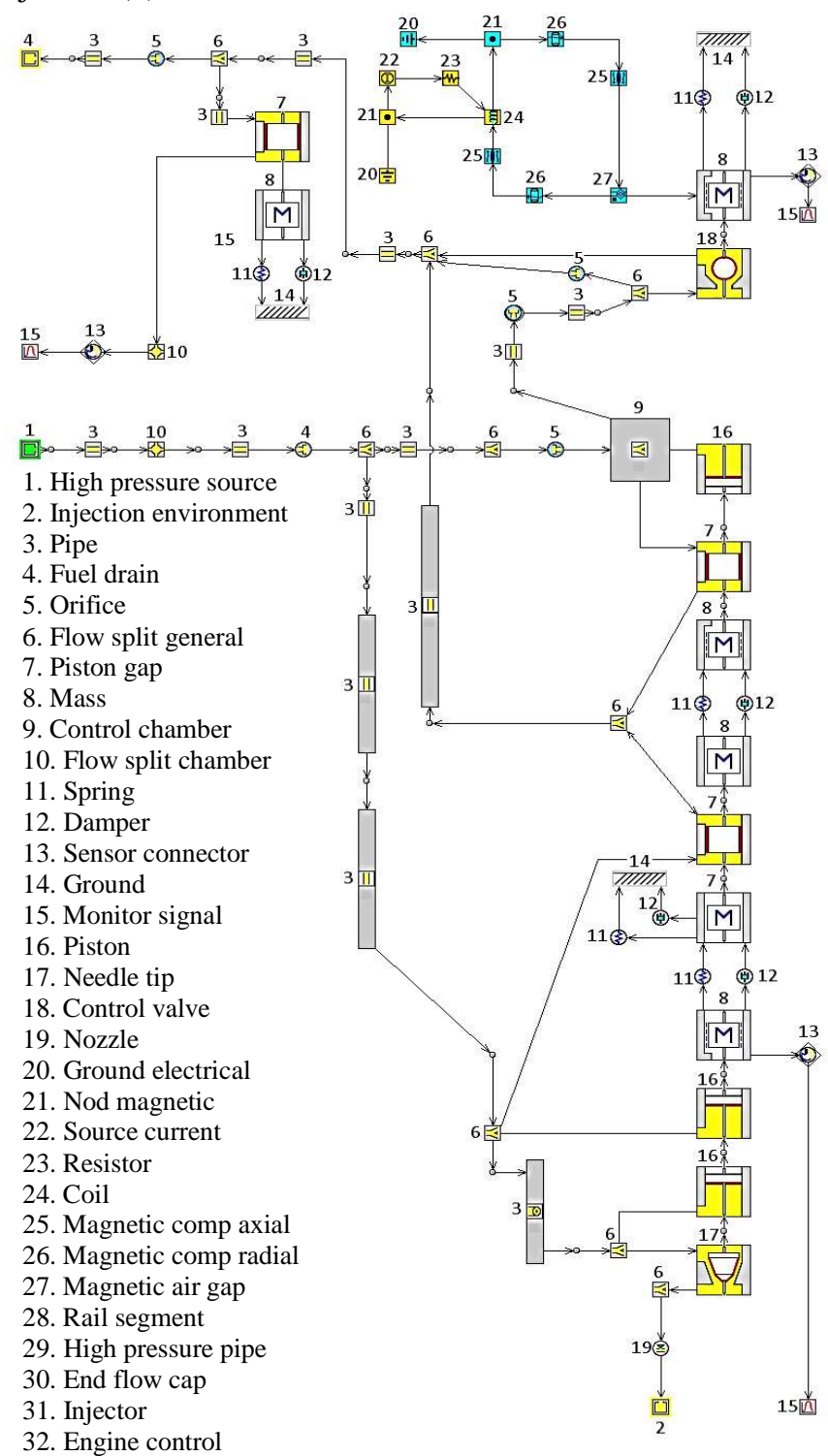

Fig. 2. 0445110376 BOSCH injector circuit in GT-SUITE.

At a later stage, the model of $0445110376 \mathrm{BOSCH}$ injectors was integrated into the model of the fuel-delivery system of a four-cylinder engine for mathematical simulation of processes associated with its operation.

To study injection processes, experimental and analytical researches were carried out. Common Rail Injector 0445110376 under nominal and extreme conditions and ISf 2.8 Cummins engine were research objects. To eliminate external factors, the experiments were carried out using CMAX3000 Common Rail Injector Test Bench (Fig. 3). The accuracy of the experiment was determined by technical characteristics of the test bench.

To verify the adequacy of the mathematical model, injector operation modes of $40 \mathrm{MPa}$ and $1000 \mathrm{MPa}$ which can be applied for both test bench and automobiles were used [10].

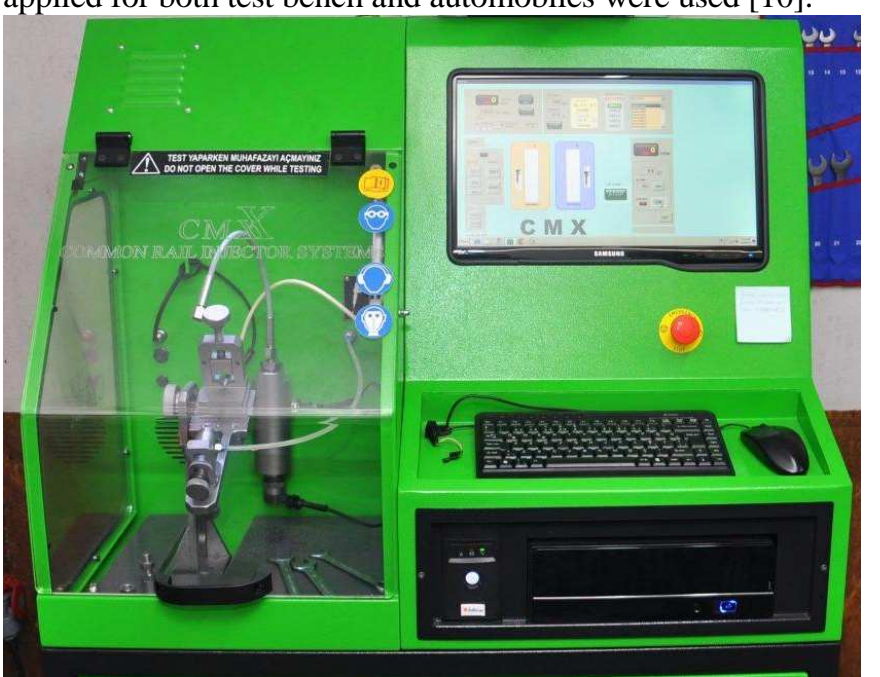

Fig 3. C-MAX 3000 Common Rail injector test bench

\section{RESULTS}

Table 1 shows calculation and experiment results of studies using CMX CRI-3000 test bed at a liquid temperature of $40^{\circ} \mathrm{C}$ and control signal frequency of $16,67 \mathrm{~Hz}$ (corresponds to 1000 pulses per minute) by delivery and 0445110376 injector control leakage (1).

\begin{tabular}{|c|c|c|c|c|c|c|c|}
\hline \multirow{2}{*}{ 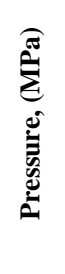 } & \multirow{2}{*}{ 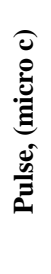 } & \multicolumn{2}{|c|}{$\begin{array}{l}\text { Delivery, } \\
\left(\mathbf{m m}^{3}\right)\end{array}$} & \multirow{2}{*}{ 莞 } & \multicolumn{2}{|c|}{$\begin{array}{l}\text { Injection back } \\
\text { leakage }\left(\mathbf{m m}^{3}\right)\end{array}$} & \multirow{2}{*}{ ब̊ } \\
\hline & & 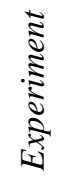 & 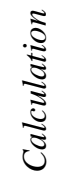 & & 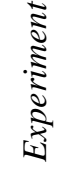 & 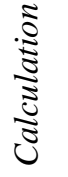 & \\
\hline \multirow{3}{*}{400} & 300 & 0.4 & 0,4 & 0 & 4.5 & 4.4 & -2.3 \\
\hline & 600 & 5.0 & 4.8 & -4.2 & 7.0 & 7.0 & 0.0 \\
\hline & 900 & 14.8 & 13.8 & -7.2 & 9.4 & 9.4 & 0.0 \\
\hline \multirow{3}{*}{1000} & 300 & 2.9 & 2,7 & -7.4 & 8.0 & 8.0 & 0.0 \\
\hline & 600 & 20.4 & 22.4 & 8.9 & 12.3 & 12.4 & 0.8 \\
\hline & 900 & 52.5 & 49.2 & -6.7 & 16,4 & 16.9 & 3.0 \\
\hline
\end{tabular}

TABLE I. ADEQUACY VERIFICATION FOR THE MATHEMATICAL MODEL OF A COMMON RAIL INJECTOR 
Experiments with injectors under nominal and extreme conditions at $40 \mathrm{MPa}$ and $100 \mathrm{MPa}$ delivered the following results (Fig. 4,5). These data can be used to assess changes in injection control leaks caused by changes in the pulse duration under the complete control signal cut-off depending on injector's conditions.

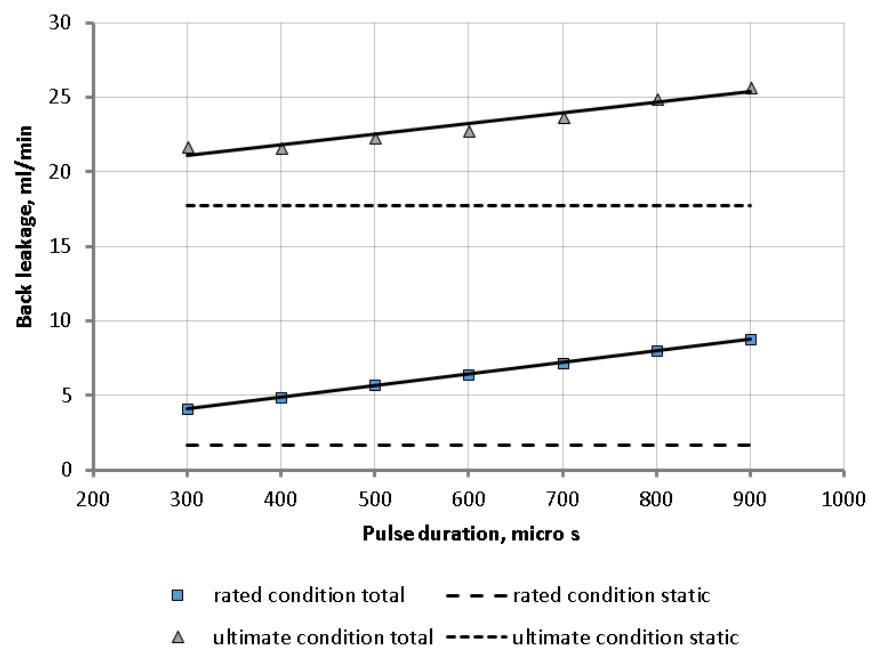

Fig. 4. Dependence of the injector control leakage at $40 \mathrm{MPa}$ on control signal changes

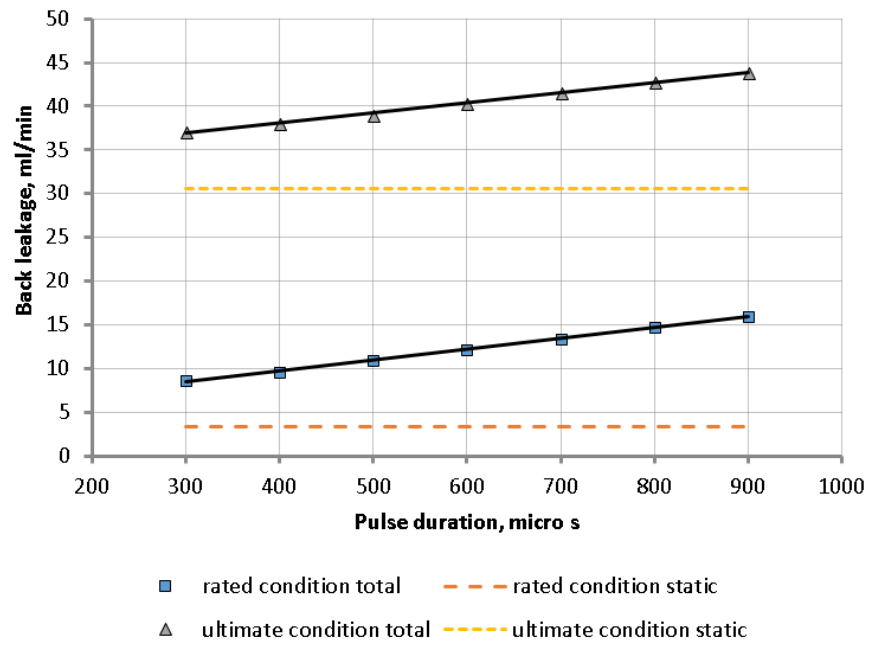

Fig. 5 Dependence of the injector control leakage at $100 \mathrm{MPa}$ on control signal changes.

\section{DISCUSSION}

Dynamic leakage is a difference between total and static leaks. The experiment identified (Fig. 4,5) insiginificant dependence of the dynamic leakage on injector's conditions. It is true if the correlations of cumulative and drain nozzles are identical

The correlation of return line leaks in injectors connected to the control signal and disconnected from the control signal is illustrative of the EHI operation.

For example, under nominal injection conditions, the correlation is 2,5 at $40 \mathrm{MPa}$ and $300 \mu \mathrm{s}$, and it is 5,3 at $900 \mu \mathrm{s}$. Under extreme injection conditions, the correlation is 1,5 and 1,4 at similar parameters. It speaks for the fact that static injection control leaks in the total leakage prevail under extreme injection conditions.

Components of the method for identifying injector leaks based on return line leaks were determined under field conditions.

Common rail leakage components allow for the development of a new EHI diagnostics method and meaningful field control of Common Rail injector's conditions.

Data on factual fuel leakage in diesel engine cylinders with an accumulator fuel-delivery system can be used to improve their ecological and economic parameters. They can be used along with well-known diagnostics methods.

\section{CONCLUSION}

The research identified relations between components of return line leaks and EHI's conditions. The relations between the cyclic delivery and fuel leakage for the nominal EHI control demonstrated the correlation of calculation and experiment results.

The analysis of dynamic and static leakage to the drain rail identified a dependence of the drain rail leakage on the connection to the control signal.

Analytical studies identified relations between fuel links, cyclic delivery and dynamic injection control leakage, which helped develop formulas for calculating these parameters.

\section{References}

[1] R. Rinolfi, R. Imarisio, R. Burati, "The potentials of a new common rail diesel fuel injection system for the next generation of DI diesel engines", VDI-Verlag Reihe, vol.12, pp. 87-111, 1998 [16 International Wiener Motor symposium].

[2] I.V. Yakimov, S.N. Krivtsov, "Analysis of fuel leaks in electrohydraulic injectors, of automobile diesel engines", Bulletin of ISTU, vol. 6, pp. 163-168, June 2016.

[3] X.L.J. Seykens, L.M.T. Somers, R.S.G. Baert, "Detailed Modeling of Common Rail Fuel Injection Process", MECCA, vol. 3, pp. 30 - 39, December 2005.

[4] M. Coppo, C. Dongiovanni, C. Negri, "Numerical analysis and experimental investigation of a common rail-type diesel injector", Journal of Engineering for Gas Turbines and Power, vol. 126, Issue 4 pp. $874-885,2004$.

[5] I.V. Yakimov, S.N. Krivtsov, "Calculation of source data for a mathematical model of an electrohydraulic injector", Bulletin of ISTU, vol. 8, pp. 182-189, August 2016.

[6] R. Payri, F.J. Salvador, P. Martí-Aldaraví, J. Martínez-López, "Using one-dimensional modeling to analyse the influence of the use of biodiesels on the dynamic behavior of solenoid-operated injectors in common rail systems: Detailed injection system model", Energy Conversion and Management, vol. 54.1, pp. 90-99, 2012.

[7] A. Piano, F. Millo, L. Postrioti, G. Biscontini, "Numerical and Experimental Assess me of a Solenoid Common-Rail Injector Operation with Advanced Injection Strategies", SAE Int. J. Engines 9(1):565-575, doi:10.4271/2016-01-0563, 2016.

[8] A.N. Vrublevskii, A.L. Grigoryev, A.M. Bovda, "Mathematical model of a quick action electric magnet for the fuel system of the combustion engine", All-Ukrainian Scientific and Technical Journal "Combustion Engine", vol. 2. pp. 138-143, 2007. 
[9] M. Coppo, C. Dongiovanni, C. Negri, "A Railar optical sensor for measuring needle displacement in common-rail diesel injectors Sensors and Actuators", A: Physical, vol. 134, Issue 2, pp. 366-373, 2007.

[10] F.J. Salvador, P. Marti-Aldaravi, M. Carreres, D. Jaramillo, "An Investigation on the Dynamic Behaviour at Different Temperatures of a
Solenoid Operated Common-Rail Ballistic Injector by means of a OneDimensional Model", SAE Technical Paper 2014-01-1089, pp. 1-17, April 2014. 